\title{
Analysis of the lgE- and lgG-reactivity profiles of asthmatic and non-asthmatic HDM-allergic patients using the ISAC microarray system
}

\author{
Yvonne Resch ${ }^{1 *}$, Sven Michel $^{2}$, Michael Kabesch ${ }^{3}$, Rudolf Valenta ${ }^{1}$, Susanne Vrtala ${ }^{4}$ \\ From 5th International Symposium on Molecular Allergology (ISMA 2013) \\ Vienna, Austria. 6-7 December 2013
}

\section{Background}

House dust mites (HDM) represent one of the most important inducers for respiratory allergies worldwide. The aim of this study was to investigate the IgE- and IgG-reactivity profiles of HDM-allergic individuals suffering only from allergic rhinitis or from allergic asthma.

\section{Methods}

This study included sera from clinically well characterized asthmatic $(\mathrm{n}=105)$ and non-asthmatic $(\mathrm{n}=53)$ HDM-allergic patients. IgE- and IgG-reactivity to seven HDM-allergens (nDer p 1, rDer p 2, rDer p 5, rDer p 7, rDer p 10, rDer p 21 and rDer p 23) were measured using a customized allergen microarray (i.e., ISAC chip, Thermofisher, Vienna, Austria).

\section{Results}

HDM-allergic individuals suffering from asthma showed striking differences regarding their IgE reactivity profiles compared to the non-asthmatic group. First, the frequency of IgE reactivity to the tested HDM allergens was up to 3fold higher in the asthmatic than in the non-asthmatic group. Seventy percent of the asthmatics reacted with 3 to 6 of the tested allergens compared to only $45 \%$ in the nonasthmatic group. Furthermore, IgE-levels to nDer p 1, rDer p 2, rDer p 5 and rDer p 23 were significantly higher in the asthmatic group. In contrast, HDM-allergic asthma patients showed a lower IgG-binding frequency to the seven HDM allergens than HDM-allergic patients without asthma.

\section{Conclusion}

The IgE and IgG reactivity profiles to HDM allergens differ considerably in patients with mild (i.e., rhinitis) and severe (i.e., asthma) respiratory symptoms due to HDM allergy.

\section{Authors' details \\ ${ }^{1}$ Medical University of Vienna, Department of Pathophysiology and Allergy Research, Vienna, Austria. ${ }^{2}$ Hannover Medical School, Dep. of Ped. \\ Pneumology, Allergy and Neonatology, Hannover, Germany. ${ }^{3}$ University Children's Hospital Regensburg (KUNO) Department of Pediatric Pneumology and Allergy, Regensburg, Germany. ${ }^{4}$ Medical University of Vienna, CD Lab. for the Development of Allergen Chips, Vienna, Austria.}

Published: 17 March 2014

\section{doi:10.1186/2045-7022-4-S2-017}

Cite this article as: Resch et al:: Analysis of the lgE- and lgG-reactivity profiles of asthmatic and non-asthmatic HDM-allergic patients using the ISAC microarray system. Clinical and Translational Allergy 2014 4(Suppl 2): 017

Submit your next manuscript to BioMed Central and take full advantage of:

- Convenient online submission

- Thorough peer review

- No space constraints or color figure charges

- Immediate publication on acceptance

- Inclusion in PubMed, CAS, Scopus and Google Scholar

- Research which is freely available for redistribution

Submit your manuscript at www.biomedcentral.com/submit
Medical University of Vienna, Department of Pathophysiology and Allergy Research, Vienna, Austria

Full list of author information is available at the end of the article 